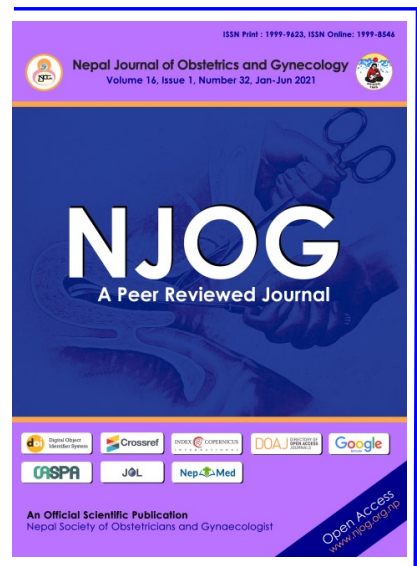

CORRESPONDENCE

Dr Rijuta Joshi (Jha)

Department of OBGYN, Patan Academy of Health Sciences, Lalitpur, Nepal

Email:

dr.rijutajoshijha@yahoo.co $\mathrm{m}$

Phone: +977-9851151830

Received: December15, 2021

Accepted: May1, 2021

\section{Citation:}

Joshi R, Baral G. Modified Risk of Malignancy Index (RMI 5) in ovarian tumor. Nep J ObstetGynecol. 2021;16(32):97-102. DOI: https://doi.org/10.3126/ njog.v16i1.37617

\title{
Modified Risk of Malignancy Index (RMI 5) in ovarian tumor
}

\author{
Rijuta Joshi, Gehanath Baral
}

Paropakar Maternity and Women's Hospital, Kathmandu

\section{ABSTRACT}

Aims: To evaluate the role of modified RMI (RMI 5) in pre-operative evaluation of ovarian tumor.

Methods: It was a prospective cross sectional study done in Paropakar Maternity and Women's Hospital from May to August 2018. During the study, 72 women with ovarian tumor were analyzed. RMI5 was calculated using the ultrasound score, Doppler score, menopausal status and CA125. Cut-off of 200 was used for malignancy discrimination. Chi square test was used to calculate the statistical significance which was set at 0.05 . Receiver Operator Characteristics curves for RMI and its individual parameters were plotted using SPSS.

Results: There were 72 ovarian tumors operated in four months and mean age was 36 years with $10(14 \%)$ at post-menopause. The mean value of RMI 5 was 38 for benign tumors, 80 for borderline tumors and 899 for malignant tumors. The area under curve for RMI 5 was 0.993 for cut-off of 200. The diagnostic accuracy of RMI 5 was 94.4 which was similar to that of Doppler score 2 (94.7) while it was much higher than that of the rest of the parameters (CA125: 72, ultrasound score: 87 and postmenopausal status: 88.9).

Conclusions: RMI 5 is better for malignancy prediction of ovarian masses instead of individual parameters like menopausal status, CA125 and ultrasound score.

Keywords: Doppler, ovarian tumor, risk of malignancy index

\section{INTRODUCTION}

Ovarian tumor is the eighth most common cancer among women worldwide. ${ }^{1}$ Although it comprises of only four percent of all women's cancer, it has high mortality and morbidity rates in comparison to the cancers of the reproductive system. ${ }^{2}$ The overall incidence of a symptomatic ovarian cyst in a premenopausal female being malignant is approximately $1: 1000$ which increases to $3: 1000$ at the age of $50 .{ }^{3} \mathrm{~A}$ preoperative estimation of the risk of malignancy is essential in the assessment of an ovarian mass. Eighty different models have been advocated for this purpose. ${ }^{3,4}$ Among the various models, simple models involve using discrete cut-off values such as Cancer Antigen-125 (CA125), pulsatility index, resistance index; intermediate models include morphology scoring systems and the risk of malignancy index (RMI) while advanced models include artificial neural networks and multiple logistic regression models. ${ }^{3}$ Among them, the RMI I and II were the best predictors. ${ }^{4}$ Jacobs et al in 1990 originally established the RMI for preoperative discrimination of ovarian malignancy. ${ }^{5}$ Tingulstad et al developed the variant of the RMI (RMI 2) in 1996 which was further modified to RMI $3{ }^{6,7}$ The RMI 3 was adjusted by Yamamoto et al to RMI $4 .{ }^{8}$ Doppler blood flow was added to the parameters of ultrasound criteria and this scoring system was termed modified RMI (RMI 5). ${ }^{9}$ When Doppler examination was used, the correct diagnosis was made with increased confidence. Malignant masses usually have the new vessels which have lower resistance to blood flow than native ovarian vessels. This has been the basis for the preoperative discrimination of malignant tumors by using Doppler. Improved performance of Doppler USG has been suggested mainly in early stage ovarian cancers or borderline tumors where correct diagnosis is difficult to make with grey scale USG only and adding Doppler decreased the false positive rate. ${ }^{10}$ Thus, this study was done to assess the 
role of RMI 5 in preoperative discrimination of the malignant ovarian masses from the benign ones.

\section{METHODS}

This prospective cross sectional study was conducted in the Department of Obstetrics and Gynecology at Paropakar Maternity and Women's Hospital (PMWH), Thapathali, Kathmandu from May to August 2018 after the approval from the Institutional Review Committee. Written informed consent was taken. There was no extra financial burden as the required tests were recorded for the purpose of treatment. Though this study is a census, considering $10.3 \%$ prevalence of adnexal mass and taking $\alpha$ error of $5 \%$ with estimated allowable error of $10 \%$, the minimum required sample was $36 .{ }^{11}$

All female patients of all age groups with ovarian mass, symptomatic or incidentally detected, scheduled for surgery were included in the study. The ovarian mass in pregnancy and cases lacking USG and CA-125 report were excluded from the study.The intraoperative findings during the surgery of all the cases were obtained from the operative notes. In cases of malignancy, staging laparotomy was done as recommended. ${ }^{12}$ The histopathological report was considered as the gold standard for defining outcomes.

Predesigned proforma was filled and RMI 5 was calculated for each case using the formula RMI $5=$ Ultrasound score (U) x Menopausal status (M) x Doppler blood flow (D) $\mathrm{x}$ absolute value of serum CA125. For Ultrasound score, score was 0 for "no features", 1 for "one features" and for 2 for " $\geq 2$ features". One point was allocated for each for the following USG features: presence of ascites, evidence of solid areas, multi-locular cyst, bilateral lesions and evidence of metastases. For menopausal status, score of 1 was given for premenopausal status and 3 for postmenopausal status. Postmenopausal status was ascertained if the woman had more than one year of amenorrhea or was over 50 years of age if she had undergone hysterectomy. For Doppler blood flow, high blood flow was graded as 2 and low blood flow was graded as 1 . Low blood flow was defined as few vessels in the tumor wall and high blood flow were defined as the vessels within the tumor wall, septa and solid areas. Cut-off of RMI 5 for malignancy was 200.

Microsoft Excel and Statistical Package for Social Sciences (SPSS 16) were used for data entry and statistical analysis. Descriptive and analytical statistics were used. Chi squared test was used to calculate the statistical significance which was set at 0.05.Receiver Operator Characteristics (ROC) curve for RMI 5 and its individual parameters were plotted using SPSS. Validity of this predictability was expressed in terms of sensitivity, specificity, positive predictive value (PPV), negative predictive value (NPV) and diagnostic accuracy (DA). Sensitivity, specificity, PPV, NPV and DA of individual parameters of RMI 5 (ultrasound score, Doppler score, postmenopausal status, CA-125) were calculated and compared with RMI5 for malignancy prediction of ovarian masses.

\section{RESULTS}

Out of 76 cases 72 were eligible for analysis with mean age of 36.3 (range: 16 - 76) years, mode of 41 $-50(n-23 ; 32 \%)$ years and seven percent $(n-5)$ were over 50 . The parity ranged from 0 to 7 . One malignant ovarian tumor was seen in $<20$ years while three were seen in $>40$ years and two of the women with malignant ovarian tumor were grandmultipara. [Table-1]

Ultrasound score, Doppler blood flow, postmenopausal status and CA 125 level were higher in malignant ovarian tumor. [Table-2]

Table-2: Distribution of cases by menopausal status, CA-125 levels, ultrasound score and Doppler score

\begin{tabular}{|c|c|c|c|c|c|}
\hline Variables & Neoplasm & Benign $(n=66)$ & $\begin{array}{c}\text { Borderline } \\
(\mathrm{n}=2)\end{array}$ & $\begin{array}{c}\text { Malignant } \\
(\mathrm{n}=4)\end{array}$ & Total $(\%)$ \\
\hline \multirow{3}{*}{ Age } & Premenopausal & 59 & 2 & 1 & $62(86)$ \\
\hline & Postmenopausal & 7 & 0 & 3 & $10(14)$ \\
\hline & Ascites & 0 & 1 & 4 & 5 \\
\hline \multirow{4}{*}{ USG } & Multi-locular cyst & 23 & 1 & 2 & 26 \\
\hline & Solid areas & 6 & 0 & 3 & 9 \\
\hline & Bilateral lesions & 16 & 0 & 0 & 16 \\
\hline & Metastases & 0 & 0 & 0 & 0 \\
\hline USG & 0 & 34 & 0 & 0 & 34 \\
\hline \multirow[t]{2}{*}{ score } & 1 & 24 & 1 & 0 & 25 \\
\hline & 2 & 8 & 1 & 4 & 13 \\
\hline \multirow{4}{*}{$\begin{array}{l}\text { Doppler } \\
\text { score }\end{array}$} & 1(low blood flow) & 14 & 0 & 0 & $14(19.4)$ \\
\hline & 2 (high blood flow) & 0 & 1 & 4 & $5(7)$ \\
\hline & Minimum & 4 & 14 & 36 & 4 \\
\hline & Maximum & 352 & 19 & 146 & 352 \\
\hline \multirow{4}{*}{ CA-125 } & Mean & 46.1 & 23.5 & 94.7 & $48.3 \pm 66.96$ \\
\hline & $<35$ & 47 & 1 & 0 & 48 \\
\hline & $35-200$ & 15 & 1 & 4 & 20 \\
\hline & $>200$ & 4 & 0 & 0 & 4 \\
\hline
\end{tabular}


There was a statistically significant difference between benign/borderline tumor and malignant tumor with respect to the ultrasound score, Doppler score, CA125, menopausal status and RMI score. [Table-3]

Table-3: Co-relation of RMI and its individual parameters with histopathology

\begin{tabular}{llcccc}
\hline & Variables & $\begin{array}{c}\text { Histopathology } \\
\text { Benign/ } \\
\text { Borderline }\end{array}$ & Malignant & Total (\%) & p-value \\
\hline USG & 0 or 1 & 62 & 0 & $62(82)$ & 0 \\
score & $2-5$ & 9 & 4 & $13(18)$ & 0.000 \\
Doppler & 1 (low blood flow) & 14 & 0 & $4(19.1)$ & 0 \\
score & 2 (high blood flow) & 1 & 4 & $5(6.84)$ & 0.000 \\
CA-125 & $<35$ & 48 & 0 & $48(65.7)$ & 0 \\
& $>35$ & 20 & 4 & $24(33.3)$ & 0.000 \\
Age & Premenopausal & 61 & 1 & $62(86.1)$ & 0 \\
& Postmenopausal & 7 & 3 & $10(13.9)$ & 0.007 \\
RMI5 & $>200$ & 64 & 0 & $64(88.9)$ & 0 \\
& $>200$ & 4 & 4 & $8(11.1)$ & 0.000 \\
\hline
\end{tabular}

The commonest ovarian tumors were endometrioma, mature cystic teratoma, cystadenoma and physiological cysts; and only 4 cases were malignant (3 in Stage IA and 1 in IC). [Table-4]

Table-4: Histopathological diagnosis of ovarian tumors

\begin{tabular}{llccc}
\hline & Histopathology & Unilateral & Bilateral & Total \\
\hline \multirow{5}{*}{ Benign } & Endometriotic cyst & 10 & 10 & 20 \\
& Mature cystic teratoma & 9 & 6 & 15 \\
& Mucinous Cystadenoma & 13 & 0 & 13 \\
& Physiological cysts & 12 & 0 & 12 \\
& Serous cystadenoma & 4 & 0 & 4 \\
& Fibroma & 1 & 0 & 1 \\
& Ovarian abscess & 1 & 0 & 1 \\
\multirow{5}{*}{ Malignanterline } & Mucinous cystadenoma & 2 & 0 & 2 \\
& Mucinous cystadenocarcinoma & 2 & 0 & 2 \\
& Clear cell carcinoma & 1 & 0 & 1 \\
& Granulosa cell tumor & 1 & 0 & 1 \\
\hline
\end{tabular}

Table-1: Distribution of cases by age and parity

\begin{tabular}{|c|c|c|c|c|}
\hline & $\begin{array}{l}\text { Neoplasms } \\
\text { leters }\end{array}$ & $\begin{array}{c}\text { Benign/ } \\
\text { Borderline }\end{array}$ & $\begin{array}{c}\text { Malig- } \\
\text { nant }\end{array}$ & Total (\%) \\
\hline \multirow{6}{*}{ 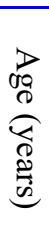 } & $<20$ & 9 & 1 & $10(13.9)$ \\
\hline & $21-30$ & 15 & 0 & $15(20.8)$ \\
\hline & $31-40$ & 19 & 0 & $19(26.4)$ \\
\hline & $41-50$ & 22 & 1 & $23(32)$ \\
\hline & $51-60$ & 2 & 1 & $3(4.1)$ \\
\hline & $>60$ & 1 & 1 & $2(2.8)$ \\
\hline \multirow{5}{*}{ 苞. } & 0 & 20 & 1 & $21(29.2)$ \\
\hline & 1 & 17 & 1 & $18(25)$ \\
\hline & 2 & 16 & 0 & $16(22.2)$ \\
\hline & 3 & 7 & 0 & $7(9.7)$ \\
\hline & $\geq 4$ & 8 & 2 & $10(13.9)$ \\
\hline
\end{tabular}

RMI 5 had predicted eight women $(11.1 \%)$ as having malignant tumors preoperatively but only half $(n=4)$ were confirmed by histopathology. Among the cases with RMI5 $>200$, the malignant cases had score of $432,476,936$ and 1752 while the four histolo gically benign cases had score of 220, 258,227 and 704. HPE of the RMI 5 unmatched cases showed mature cystic teratoma (1), endometriomas (2) and follicular cyst (1).

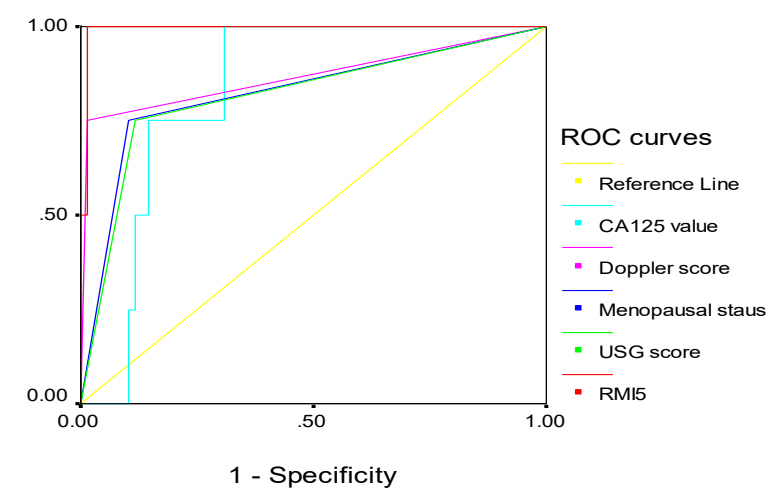

Chart-1: ROC curves for RMI 5 and its individual parameters 
The two cases of mucinous borderline cystadenoma had CA125 of 19, 40 and RMI 5 of 0,160 . The four cases of histologically malignant tumors had CA125 of 36, 78, 119 and 146. The mean value of RMI 5 was 38.46 (R: 0-704) for benign lesions, 80 (R: 0-160) for borderline tumors and 899 (R: 432-1752) for malignant tumors. The highest specificity (94.11) was for RMI 5 followed by that of Doppler score (93.3). The DA of RMI 5 was 94.44 which was comparable to that of Doppler score (94.7). CA125 had the least DA of $72.2 \%$ for prediction of malignancy. [Table-5]

Table-5: Predictive values of RMI 5 and its components

\begin{tabular}{lccccccc}
\hline \multicolumn{1}{c}{ Variables } & $\begin{array}{c}\text { Sensitivity } \\
(\%)\end{array}$ & $\begin{array}{c}\text { Specificity } \\
(\%)\end{array}$ & $\begin{array}{c}\text { PPV } \\
(\%)\end{array}$ & $\begin{array}{c}\text { NPV } \\
(\%)\end{array}$ & $\begin{array}{c}\text { DA } \\
(\%)\end{array}$ & $\begin{array}{c}\text { Positive } \\
\text { LR }\end{array}$ & $\begin{array}{c}\text { Negative } \\
\text { LR }\end{array}$ \\
\hline CA-125 $>35 \mathrm{U} / \mathrm{mL}$ & 100 & 70.5 & 16.6 & 100 & 72.2 & 3.3 & 0 \\
USG score $\geq 2$ & 100 & 86.76 & 30.7 & 100 & 87.5 & 7.1 & 0 \\
Doppler score 2 & 100 & 93.3 & 80 & 100 & 94.7 & 14.9 & 0 \\
Post-menopause & 75 & 89.7 & 30.3 & 98.3 & 88.9 & 9.0 & 0.2 \\
RMI5 & 100 & 94.11 & 50 & 100 & 94.44 & 17.2 & 0 \\
\hline NB. PPV-Positive predictive value; NPV-Negative predictive value; DA-Diagnostic accuracy; LR- \\
Likelihood ratio
\end{tabular}

In ROC curve, the area under curve for RMI5 is 0.993 and p of 0.001 . For cut-off of 345 , sensitivity was 1 and (1-specificity) was 0.015 while for cut-off of 242 it was $(1,0.029)$ and for 223 it was $(1,0.044)$ respectively. [Figure-1, Table-6]

Table-6: AUC of RMI 5 and its individual parameters

\begin{tabular}{lccccc}
\hline Variables & \multirow{2}{*}{ Area } & $\begin{array}{c}\text { Std. } \\
\text { Error }\end{array}$ & $\begin{array}{c}\text { Asymptotic } \\
\text { Sig. }\end{array}$ & $\begin{array}{c}\text { Asymptotic 98\% Confidence Interval } \\
\text { Lower Bound }\end{array}$ & \begin{tabular}{c} 
Upper Bound \\
\hline RMI5
\end{tabular} \\
USG Score & 0.993 & 0.009 & 0.001 & 0.972 & 1.013 \\
Menopause & 0.816 & 0.129 & 0.034 & 0.516 & 1.117 \\
Doppler score & 0.868 & 0.129 & 0.031 & 0.523 & 1.124 \\
CA125 Value & 0.831 & 0.057 & 0.013 & 0.564 & 1.171 \\
\hline
\end{tabular}

\section{DISCUSSION}

Preoperative assessment of ovarian masses can be done with tumor markers, gray-scale ultrasonographic criteria, Doppler velocimetry, and 3dimensional ultrasound. CA125 is a protein molecule made by normal cells as well as ovarian cancer cells and its high levels in blood raises the suspicion of ovarian malignancy so it is recommended as the tumor marker in all women with ovarian masses. ${ }^{13-15}$ However, CA125 has not been found to be sensitive enough to detect malignancy in early stages and it is raised in multiple other diseases including the endometriosis. ${ }^{15,16}$ In this study, all the malignant disease were of early stage and did not have high values of CA-125 (36, 78, 119 and 146).However, the mean value of CA125 for the malignant lesions was higher than for benign/ borderline counterparts ( 94.7 vs $46.1,23.5)$.

Similar to this study, subjective score of vascular flow (visual scores) was "abundant" in $78 \%$ of malignant tumors and "low" on $73 \%$ of benign tumors in other study. ${ }^{17}$ They found the sensitivity for discriminating malignant lesion to be $100 \%$ for both Power Doppler Index and Visual scores 2 (moderate) and 3 (abundant) while the specificity to be $97 \%$ and $73.1 \%$ respectively. In a study, USG using B-mode morphological criteria and Doppler analysis (RI,PI) showed overall sensitivity of $94 \%$ and specificity of $90 \% .{ }^{18}$ Similar finding was seen in other studies. ${ }^{19,20}$ In this study, the DA of Doppler score 2 (high blood flow) was $94.7 \%$ with specificity of $93 \%$ and PPV of $80 \%$.

RMI has been found to be useful to triage the patients with adnexal masses especially in the centers where sophisticated radiological and biochemical tests are not available. ${ }^{21}$ There were no statistically significant difference in the performance of the RMI 1 to 4 in discriminating malignancy and were more reliable than the individual parameters. ${ }^{22}$ Similar finding was seen in study in other studies. ${ }^{23,24}$ Likewise, in this study, RMI 5 is better in comparison to its individual parameters for detection of malignancy. The diagnostic accuracy of RMI 5 is 94.44 which is similar to that of Doppler score 2 (94.7) while it is much higher than that of the rest of the parameters (CA-125: 72.2, Ultrasound score: 87.5 and postmenopausal status: 88.9). In a study done by Hayman FM et al, compared to RMI 1-4, RMI 5 was found to have increa 
sed sensitivity in detecting malignant masses. ${ }^{9}$ In their study, the commonest benign pathology was mature cystic teratoma (29\%) and endometrioma $(20 \%)$ which is comparable to this study. However they had higher percentage of malignant tumors $(56 \%)$ and of higher stages (Stage 2 and more: $55.6 \%)$. The cut-off value for RMI 5 was 220 which is comparable with this study. In their study, sensitivity and NPV is lesser (82Vs $100 \%$; 90 vs $100 \%$ ) while specificity is similar (92 vs $94 \%$ ). However, their PPV is much higher ( $86 \mathrm{Vs} 50 \%$ ). There was a statistically significant difference in RMI 5 values between the benign and malignant masses, which is similar to this study. The AUC is higher for RMI 5 (0.993) in this study as compared to that of RMI 1-4 $(0.825,0.826,0.825,0.826){ }^{22}$ At cut-off of 223 , sensitivity of RMI 5 is 100 and specificity is $95.6 \%$ while at 345 , it is 100 and $98.5 \%$ respectively. At higher cut-off values, the specificity increases at the expense of sensitivity and higher values are chosen when false positives are required to be at minimum. Similar findings have been noted in other studies. ${ }^{21,22}$ Compared to its individual parameters, the AUC of the RMII 5 was the highest (0.99) followed by that of the Doppler score (0.86).

\section{CONCLUSIONS}

RMI 5 is better for diagnosis of ovarian malignancy instead of individual parameters like menopausal status, CA125 and ultrasound score.

\section{EFERENCES}

1. Ferlay J, Soerjomataram I, Ervik M, Dikshit R, Eser S, Mathers C, et al. GLOBOCAN 2012 v1.1, Cancer Incidence and Mortality Worldwide: IARC CancerBase No. 11 [Internet]. Lyon, France: International Agency for Research on Cancer; 2014.

2. Sankaranarayanan R, Ferlay J. Worldwide burden of gynaecological cancer: the size of the problem. Best Prac Res ClinObstetGynaecol. 2006;20(2):207-25.

3. RCOG/BSGE Joint Guideline. Management of suspected ovarian masses in premenopausal women. Green-top Guideline No. 62; 2011.

4. Geomini P, Kruitwagen R, Bremer GL, Cnossen $\mathrm{J}$, Mol BW. The accuracy of risk scores in predicting ovarian malignancy: a systematic review. Obstet Gynecol. 2009;113:384-94.

5. Jacobs, Oram D, Fairbanks J, Turner J, Frost C, Grudzinskas JG. Risk of malignancy index incorporating CA 125 , ultrasound and menopausal status for the accurate preoperative diagnosis of ovarian cancer. BJOG. 1990;97(10):922-9.

6. Tingulstad S, Hagen B, Skjeldestad FE, Onsrud M, Kiserud T, Halvorsen T, Nustad K. Evaluatio $\mathrm{n}$ of a risk of malignancy index based on serum CA125, ultrasound findings and menopausal status in the pre-operative diagnosis of pelvic masses. BJOG. 1996;103(8):826-1.

7. Tingulstad S, Hagen B, Skjeldestad FE, Halvorsen T, Nustad K, Onsrud M. Therisk-ofmalignancy index to evaluate potential ovarian cancers in local hospitals. Obstet Gynecol. 1999; 93:448-52.

8. Yamamoto Y, Yamada R, Oguri H, Maeda N, Fukaya T. Comparison of four malignancy risk indices in the preoperative evaluation of patients with pelvic masses. Eur J Obstet Gynecol Reprod Biol. 2009;144:163-7.

9. Hayam FM, Ashraf MQ, Hassan MKH. Assessment of the value of a Modified Risk of Malignancy Index (RMI) in preoperative discrimination between benign and malignant ovarian masses. Gynecol Obstet. 2016;6:417.

10.Valentin L. Prospective cross-validation of Doppler ultrasound examination and gray-scale ultrasound imaging for discrimination of benign and malignant pelvic masses. Ultrasound Obstet Gynecol. 1999;14:273-83.

11.Paropakar Maternity and Women's Hospital. SMARIKA-2075. Hospital Admission Record. Unpublished.

12.Prat J. Staging classification for cancer of the ovary, fallopian tube, and peritoneum. Int J Gynecol Obstet. 2014;124(1):1-5.

13.NCCN Guideline for patients. Ovarian cancer. Version 1;2017. URL: www.ncen.org.

14.Clinical guideline. NICE. Ovarian cancer: recognition and initial management;2011.

15.RCOG. The management of ovarian cysts in postmenopausal women. Green-top Guideline No. 34.2016.

16.Kobayashi E, Ueda Y, Matsuzaki S, Yokoyama $\mathrm{T}$, Kimura T, Yoshino $\mathrm{K}$ et al. Biomarkers for screening, diagnosis, and monitoring of ovarian cancer .Cancer Epidemiol Biomarkers Prev. 2012;21:1902-12.

17. Marret H, Sauget S, Giraudeau B, Body G, Tranquart F. Power Doppler vascularity index for predicting malignancy of adnexal masses. Ultrasound Obstet Gynecol. 2005; 25:508-13.

18.Gupta KP, Jain SK. Role of ultrasonography and color doppler to diagnosis of pelvic masses and its correlation with histopathological findings. Int J Sci Stud. 2016;4(3):147-53

19. Malhotra A, Tarafdar S, Tayade AT. Benign versus malignant adnexal masses: does addition 
of color and spectral Doppler over and above the gray scale ultrasound improves diagnostic efficacy. Sch J App Med Sci. 2016; 4(1A):62-74.

20. Goyal M, Agarwal VK. Diagnostic accuracy of B-mode USG and Doppler scan for ovarian lesions. JCDR. 2016;10(9):TC01.

21.Dora SK, Dandapat AB, Pande B, Hota JP. A prospective study to evaluate the risk malignancy index and its diagnostic implication in patients with suspected ovarian mass. J Ov Res. 2017;10:55

22. Aktürk E, Karaca RE, Alanbay I, Dede M, Karaşahin E, Yenen MC et al. Comparison of four malignancy risk indices in the detection of malignant ovarian masses. J Gynecol Oncol. 2011;22(3):177-82
23. Yelikar KA, Deshpande SS, Nanaware SS, Pagare SB. Evaluation of the validity of risk malignancy index in clinically diagnosed ovarian masses and to compare it with the validity of individual constituent parameter of risk malignancy index. Int J Reprod Contracept Obstet Gynecol. 2016;5:460-4.

24.Javdekar R, Nandita M. Risk of Malignancy Index (RMI) in evaluation of adnexal mass. J Obstet Gynecol India. 2015;65(2):117-21. 